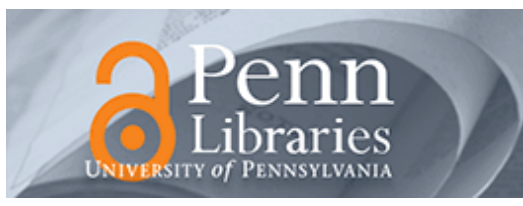

University of Pennsylvania ScholarlyCommons

Wharton Pension Research Council Working

Papers

Wharton Pension Research Council

4-1-2010

\title{
Ricardian Equivalence Under Asymmetric Information
}

Kent A. Smetters

The Wharton School, University of Pennsylvania, smetters@wharton.upenn.edu

Shinici Nishiyama

Georgia State University, snishiyama@gsu.edu

Follow this and additional works at: https://repository.upenn.edu/prc_papers

Part of the Economics Commons

Smetters, Kent A. and Nishiyama, Shinici, "Ricardian Equivalence Under Asymmetric Information" (2010). Wharton Pension Research Council Working Papers. 191.

https://repository.upenn.edu/prc_papers/191

This paper is posted at ScholarlyCommons. https://repository.upenn.edu/prc_papers/191

For more information, please contact repository@pobox.upenn.edu. 


\title{
Ricardian Equivalence Under Asymmetric Information
}

\begin{abstract}
Several empirical studies have found that extended household units do not appear to be highly altruistically linked, thereby violating the very premise of the Ricardian Equivalence Hypothesis $(\mathrm{REH})$. This finding has a very strong implication for the effectiveness of fiscal policies that change the allocation of resources between generations. We build a two-sided altruistic-linkage model in which private transfers are made in the presence of two types of shocks: an "observable" shock that is public information (for example, a public redistribution like debt or pay-as-you-go social security) and an "unobservable" shock that is private information (for example, individual wage innovations). Parents and children observe each other's total income but not each other's effort level. In the second-best solution, unobservable shocks are only partially shared, whereas, for any utility function satisfying a condition derived herein, observable shocks are fully shared. The model, therefore, can generate the low degree of risk sharing found in previous empirical studies, but REH still holds.
\end{abstract}

\section{Keywords}

Market Shocks, Household, Altruism, Optimal, Hazard, Equilibrium, Symetric, Ricardian

\section{Disciplines}

Economics 


\section{Ricardian Equivalence Under Asymmetric Information}

Kent A. Smetters and Shinici Nishiyama

April 2010

\section{PRC WP2010-05 \\ Pension Research Council Working Paper Pension Research Council}

The Wharton School, University of Pennsylvania

3620 Locust Walk, 3000 SH-DH

Philadelphia, PA 19104-6302

Tel: 215.898.7620 Fax: 215.573.3418

Email: prc@wharton.upenn.edu

http://www.pensionresearchcouncil.org

We thank seminar participants at Berkeley, MIT, Stanford and the NBER. Opinions and conclusions are solely those of the author(s) and do not reflect views of the institutions supporting the research, with whom the authors are affiliated, or the Pension Research Council. Copyright 2010 @ Pension Research Council of the Wharton School of the University of Pennsylvania. All rights reserved. 


\title{
Ricardian Equivalence Under Asymmetric Information
}

\author{
Kent A. Smetters and Shinici Nishiyama
}

Several empirical studies have found that extended household units do not appear to be highly altruistically linked, thereby violating the very premise of the Ricardian Equivalence Hypothesis (REH). This finding has a very strong implication for the effectiveness of fiscal policies that change the allocation of resources between generations. We build a two-sided altruistic-linkage model in which private transfers are made in the presence of two types of shocks: an "observable" shock that is public information (for example, a public redistribution like debt or pay-as-you-go social security) and an "unobservable" shock that is private information (for example, individual wage innovations). Parents and children observe each other's total income but not each other's effort level. In the second-best solution, unobservable shocks are only partially shared, whereas, for any utility function satisfying a condition derived herein, observable shocks are fully shared. The model, therefore, can generate the low degree of risk sharing found in previous empirical studies, but REH still holds. 


\section{Introduction}

According the Ricardian Equivalence Hypothesis (REH), altruistically-linked households alter their private intergenerational transfers to offset changes in the timing of public taxes and transfers, thereby neutralitizing the public program’s effectiveness (Ricardo, 1820, reprinted in 1951; Barro, 1974). Tax timing changes include a government budget deficit or an increase in pay-as-you-go social security spending, which shift resources from the younger to older cohorts. Under REH, these tax transfers are offset by larger bequests from parents to their children, undoing their effectiveness. Budget deficits and reforms like a move toward a funded Social Security system effectively become irrelevant. It is not surprising, therefore, that REH has generated a very lively debate during the past three decades. See, for example, the literature reviews in Bernheim (1987), Weil (1989), Seater (1993), Barro (1998), Elmendorf and Mankiw (1999), and Smetters (1999).

While many economists do not believe that Ricardian equivalence is a close description of reality, ${ }^{1}$ the actual empirical evidence is mixed, especially when analyzing aggregate data (see reviews by Seater 1993; Congressional Budget Office 1998). Household-level data sets, however, have become more widely available in the past two decades, thereby allowing for a more direct test of the altruism tenet underlying Ricardian equivalence. The earliest work by Tomes (1981) and Bernheim (1991) find some limited evidence in favor of the altruism model. Page (2003) shows that intergenerational transfers made by many households are sensitive to differences in tax rates across U.S. states, consistent with altruism. But, in an important series of papers, Altonji, Hayashi, and Kotlikoff (1992, 1997) and Hayashi, Altonji, and Kotlikoff (1996) demonstrate that the evidence for altruism is likely well below that needed to support REH. For example, AHK (1997) estimate that a \$1 decrease in permanent income of a child combined with a \$1 increase in permanent income of his/her parents produces less than a $\$ 0.13$ increase in private transfer from parent to child - much less than the \$1 transfer required by REH. ${ }^{2}$ Consistently, Wilhelm (1996) finds little evidence

\footnotetext{
${ }^{1}$ For example, in Slemrod's (1995) survey of the National Tax Association (including 521 academics, 406 government employees, and 381 private-sector employees), 89 percent of those responding replied in the affirmative to the question, "Does a large federal budget deficit have an adverse effect on the economy?"

${ }^{2}$ Other authors have regressed consumption growth on income growth in order to test for the presence of risk sharing outside of the family. See Cochrane (1991), Mace (1991), and Townsend (1994). Altuğ and Labadie
} 
that bequests compensate for earnings differences between parents and children. While Cox, Hansen, and Jimenez (2004) find evidence of risk sharing in a developing economy, it is at a level well short of the full offset predicted by the altruistic-linkage model.

In this paper, we demonstrate that the conventionally estimated low level of risk sharing between parent households and child households is not necessarily inconsistent with the Ricardian Equivalence Hypothesis. We build a two-sided altruistic-linkage model in which private transfers are made in the presence of two types of shocks: an "observable" shock that is public information among households (for example, public redistribution) and an "unobservable” shock that is private information (for example, idiosyncratic wages). Parents and children observe each other's total income but not each other's endogenous level of labor market effort. A risk-sharing arrangement contingent on effort level (the first-best solution), therefore, is not possible. In the second-best solution, unobservable shocks are only partially shared in the presence of moral hazard (slack). But, observable shocks (for example, tax timing changes) will be fully shared provided that the utility function satisfies a condition derived herein. As a result, our model can reproduce the low degree of risk sharing found in recent empirical studies, but REH (the private offset of public transfers) still holds.

The paper is organized as follows. Section 2 sets up the basic principal-agent model between parents and their children. Section 3 demonstrates how familial risk-sharing arrangements distort work incentives (that is, create moral hazard) when first-best arrangements are not possible. Section 4 formally derives the first-best and second-best optimal risk-sharing arrangements. Section 5 presents some examples of utility functions in which Ricardian equivalence holds in the presence of a potentially low level of observed risk sharing. Section 6 discusses the interdependence of the risk-sharing arrangements for observable and unobservable shocks in the second-best equilibrium. Section 7 concludes the paper.

\section{The Model}

\subsection{Income Shocks and Risk-Sharing Arrangements}

Consider two altruistic households, $i \in\{1,2\}$, specifically, parents and children. Each household receives two types of income shocks, $s_{i}$ and $t_{i}$. The shock $s_{i}$ is an idiosyncratic (1994) discuss the empirical methodology in detail. 
income shock to household $i$ that is unobservable to the other household, $-i$. The shock $t_{i}$ is a government tax transfer to household $i$ that is observable to both households. The cumulative probability distributions for $s_{i}$ and $t_{i}, F\left(s_{i}\right)$ and $G\left(t_{i}\right)$, are independent, and the corresponding density functions are symmetric around zero. ${ }^{3}$ So, $E\left(s_{i}\right)=E\left(t_{i}\right)=0$.

The pre-transfer labor income $y_{i}$ of household $i$ (that is, before observable shocks) is defined as the sum of its unobservable effort level ("hours worked"), $h_{i}$, and unobservable shock $s_{i}$, that is,

$$
y_{i}=h_{i}+s_{i} .
$$

The sum $y_{i}$ is observable, but its components are not independently observable, prohibiting first-best risk sharing. ${ }^{4}$

Both types of shocks can be shared among households. Let $\sigma \in[0,0.5]$ be the risksharing plan for unobservable shocks $s_{i}$. In particular, $\sigma$ is equal to the proportion of the unobservable shock, $s_{i}\left[s_{-i}\right]$, that is shared by the other household, $-i[i]$. The risk-sharing plan $\sigma=0$ indicates no risk sharing, while $\sigma=0.5$ indicates perfect risk sharing (equal division of income). Similarly, let $\tau \in[0,0.5]$ denote the risk-sharing plan for the observable shock $t_{i}$. In particular, $\tau$ is equal to the proportion of the observable shock, $t_{i}\left[t_{-i}\right]$, that is shared by the other household, $-i[i]$. Similarly, the risk-sharing plan $\tau=0$ indicates no risk sharing, and $\tau=0.5$ indicates full risk sharing. The notation for the model is summarized in Table 1.

\subsection{The Timing of the Model}

The timing of the households' actions is as follows:

1. Two households determine the risk-sharing plan $(\sigma, \tau)$ based on the distributions of the shocks, $F\left(s_{i}\right)$ and $G\left(t_{i}\right)$, and the degree of altruism $\phi$ that is part of their utility

\footnotetext{
${ }^{3}$ In particular, $s_{i}$ and $t_{i}$ are independent for all $i$. Moreover, $s_{i}$ and $s_{j}$ (and $t_{i}$ and $t_{j}$ ) are independent for $i \neq j$.

${ }^{4}$ Hence, our model has some similarities with the optimal income tax literature started by Mirrlees, which also assumes that the government cannot observe hours worked. While parents with children living under the same roof might be in a slightly better position than the government to monitor hours worked by their children, most parents are still not able to monitor many key variables captured by our $h$ term including job performance, hours spent looking for work, and so on. For households not living under the same roof (constituting most of the sample in the empirical studies referenced in Section 1), observing hours worked is also difficult.
} 


\begin{tabular}{lll}
\hline$i$ & $\in\{1,2\}$ & Household \\
$y_{i}$ & $\in \mathbf{R}$ & Labor income (earnings) \\
$h_{i}$ & $\in[0,1)$ & Effort (working hours) \\
$c_{i}$ & $\in \mathbf{R}_{+}$ & Consumption of goods \\
$l_{i}$ & $\in(0,1]$ & Leisure \\
$\phi$ & $\in[0,1]$ & Degree of altruism \\
$s_{i}$ & $\in \mathbf{R}$ & Unobservable shock to household $i$ 's resources \\
$t_{i}$ & $\in \mathbf{R}$ & Observable shock to household $i$ 's resources \\
$\sigma$ & $\in[0,0.5]$ & Proportion of unobservable shock, $s_{i}\left[s_{-i}\right]$, shared by household $-i[i]$ \\
$\tau$ & $\in[0,0.5]$ & Proportion of observable shock, $t_{i}\left[t_{-i}\right]$, shared by household $-i[i]$ \\
$F\left(s_{i}\right)$ & $\in[0,1]$ & Cumulative probability distribution for the unobserved shock $s_{i}$ \\
$G\left(t_{i}\right)$ & $\in[0,1]$ & Cumulative probability distribution for the observed shock $t_{i}$ \\
\hline
\end{tabular}

function (shown below);

2. Each household decides its working hours (effort level), $h_{i}$ and $h_{-i}$;

3. Two types of shocks, $\left(s_{i}, s_{-i}\right)$ and $\left(t_{i}, t_{-i}\right)$, are realized;

4. Income is redistributed between households on the basis of the risk-sharing arrangement, $(\sigma, \tau)$.

\subsection{The Household Problem and Optimal Effort, $h$}

Altonji, Hayashi, and Kotlikoff (1992) (herein AHK) present a one-sided altruism model with inelastic effort in which parents and children overlap for two periods. Parents and children face earnings uncertainty only over the second overlapping period. AHK demonstrate that all inter-generational transfers will occur only in the second period unless a child is liquidity constrained in the first period. ${ }^{5}$ We extend the AHK model to allow for two-sided altruism as well as an endogenous level of effort. The focus on two-sided altruism not only allows for cleaner analytical derivations, it also gives the REH the best chance of holding in the presence of imperfect risk sharing. Showing that REH is compatible in the presence of the evidence of imperfect risk sharing is the core motivation of this paper. Since our focus is on the role of

\footnotetext{
${ }^{5}$ Since altruism is one-sided in the AHK framework, a transfer in the first period cannot be undone in the second period. Parents, therefore, value the option to delay their transfers in order to get more information about their child's lifetime income, which includes second-period income.
} 
moral hazard and not liquidity constraints, we also focus on the second overlapping period. ${ }^{6}$

The two households place an equal weight, $\phi$, on each other's utility, where $\phi=1$ indicates full altruism and $\phi=0$ indicates no altruism. Household $i$ 's problem, therefore, is

$$
\max _{c_{i}, l_{i}} E\left[u\left(c_{i}, l_{i}\right)+\phi u\left(c_{-i}, l_{-i}\right)\right]
$$

subject to

$$
\begin{aligned}
c_{i} & =(1-\sigma) y_{i}+\sigma y_{-i}+(1-\tau) t_{i}+\tau t_{-i} \\
c_{-i} & =(1-\sigma) y_{-i}+\sigma y_{i}+(1-\tau) t_{-i}+\tau t_{i} \\
l_{i} & =1-h_{i}, \\
l_{-i} & =1-h_{-i} .
\end{aligned}
$$

Notice that household $i$ 's consumption is dependent on its own income, $y_{i}$, as well as the income of household $-i, y_{-i}$. Household $i$ keeps $(1-\sigma)$ of its own income, $y_{i}$, and shares the remaining fraction, $\sigma$, with household $-i$. Conversely, it receives $\sigma$ fraction of the income from household $-i$. The observable tax transfers, $t_{i}$ and $t_{-i}$, are similarly shared.

Substituting $c_{i}, c_{-i}, l_{i}$, and $l_{-i}$ into the utility function with $y_{i}=h_{i}+s_{i}$, the problem becomes

$$
\begin{aligned}
\max _{h_{i}} E & {\left[u\left((1-\sigma)\left(h_{i}+s_{i}\right)+\sigma\left(h_{-i}+s_{-i}\right)+(1-\tau) t_{i}+\tau t_{-i}, 1-h_{i}\right)\right.} \\
& +\phi u\left[u\left((1-\sigma)\left(h_{-i}+s_{-i}\right)+\sigma\left(h_{i}+s_{i}\right)+(1-\tau) t_{-i}+\tau t_{i}, 1-h_{-i}\right)\right] .
\end{aligned}
$$

The first-order condition with respect to $h_{i}$ is

$$
(1-\sigma) E u_{c}\left(c_{i}, l_{i}\right)-E u_{l}\left(c_{i}, l_{i}\right)+\phi \sigma E u_{c}\left(c_{-i}, l_{-i}\right)=0
$$

The Ricardian Equivalence Hypothesis considers how parents and children respond to shocks that are symmetric ex post: $s_{-i}=-s_{i}$ and $t_{-i}=-t_{i}$. Specifically, REH focuses

\footnotetext{
${ }^{6}$ This assumption is without loss in generality since, without liquidity constraints, transfers would not occur in the first period even with two-sided altruism when it is less than full $(\phi<1)$. Conceptually, in this case, therefore, we could capture the effect of first-period assets, $a_{i}$, by redefining the pre-transfer income of agent $i$ as $\widetilde{y}_{i}=y_{i}+a_{i}=h_{i}+s_{i}+a_{i}$. For the same reason that the assumption $E\left(s_{i}\right)=0$ is irrelevant (as explained in an earlier footnote), the addition of linear terms, which are taken as given in the second period, are also irrelevant. In the case in which altruism is full $(\phi=1)$, the timing of inter-generational transfers is ambiguous but moral hazard - and, hence, imperfect risk sharing - does not exist either, as shown below. This case, therefore, is not important for showing how Ricardian equivalence can exist with imperfect risk sharing.
} 
on shocks that are realized to be symmetric; the shocks are not anticipated to be symmetric ex ante. Ex post symmetric shocks are always insurable within two households; REH posits that they will, in fact, be fully insured. The above first-order condition, however, is an ex ante condition: neither parent or child knows how the shock of the other household is correlated with its own shock when decided its own policy (optimal response) function. Consistent with REH, we also only analyze realized shocks that are symmetric; considering realized non-symmetric shocks would add cubersome notation without providing any greater insights into the test of REH itself.

The income of household $i$ after risk sharing, therefore, is defined as

$$
(1-\sigma) y_{i}+\sigma y_{-i}=(1-\sigma) h_{i}+\sigma h_{-i}+(1-2 \sigma) s_{i}
$$

where we used the fact that $s_{-i}=-s_{i}$. The amount of the observable shock borne by household $i$ after risk sharing, therefore, is

$$
(1-\tau) t_{i}+\tau t_{-i}=(1-2 \tau) t_{i}
$$

where we used the fact that $t_{-i}=-t_{i}$.

By the symmetric assumption, the expected utilities of the two households are then the same, that is,

$$
E u_{c}\left(c_{i}, l_{i}\right)=E u_{c}\left(c_{-i}, l_{-i}\right)
$$

Substituting this equation into our first-order condition produces: ${ }^{7}$

$$
(1-\sigma+\phi \sigma) E u_{c}\left(c_{i}, l_{i}\right)-E u_{l}\left(c_{i}, l_{i}\right)=0
$$

Moreover, the optimal working hours of the two households are the same, that is,

$$
h_{i}=h_{-i}=h,
$$

\footnotetext{
${ }^{7}$ For purposes of clarity, notice that the symmetric shock relationships are imposed after the first-order condition has been derived, not before. This distinction is important: imposing the symmetric relationship before the first-order condition is derived would mean that agent knows the symmetric shock condition ex ante. In contrast, imposing the symmetric condition after the first-order is derived implies that the agent does not anticipate symmetry; rather, equation (5) simply examines the agent's optimal response conditional on the symmetric shock being realized.
} 
and the optimal working hours, $h\left(\sigma, \tau ; \phi, F\left(s_{i}\right), G\left(t_{i}\right)\right)$, solve

$$
\begin{gathered}
(1-\sigma+\phi \sigma) E u_{c}\left(h+(1-2 \sigma) s_{i}+(1-2 \tau) t_{i}, 1-h\right) \\
-E u_{l}\left(h+(1-2 \sigma) s_{i}+(1-2 \tau) t_{i}, 1-h\right)=0 .
\end{gathered}
$$

\section{The Impact of Risk Sharing on Effort}

Although it is difficult to solve for $h$ analytically since we have not yet specified a utility function, this section characterizes how the optimal working hours vary with the risk-sharing plan, $(\sigma, \tau)$. Toward this end, we make some standard assumptions about the utility function. Utility is increasing in the level of the consumption of goods and leisure but at a decreasing rate $\left(u_{c}>0, u_{l}>0, u_{c c}<0, u_{l l}<0\right)$; the marginal utility of consumption and leisure might be separable or nonseparable provided that it is nondecreasing in the level of the other $\left(u_{c l}=u_{l c} \geq 0\right)$ but at a nonincreasing rate $\left(u_{c c l}=u_{c l c}=u_{l c c} \leq 0 ; u_{l l c}=u_{l c l}=u_{c l l} \leq 0\right)$; agents do not exhibit imprudence $\left(u_{c c c} \geq 0\right){ }^{8}$

Lemma 1 (Impact of $\sigma$ on effort, $h$ )

(1) When two households are not fully altruistic to each other $(0 \leq \phi<1)$, the optimal level of effort, $h$, is strictly decreasing in the amount of the unobservable shock that is shared by the other household, $\sigma$, for all $\sigma \in[0,0.5]$.

(That is, $\phi<1 \Longrightarrow \frac{\mathrm{d}}{\mathrm{d} \sigma} h(\sigma, \tau)<0$ for $\sigma \in[0,0.5]$.)

(2) When two households are fully altruistic to each other $(\phi=1)$, the optimal level of effort, $h$, is unaffected by a small change in $\sigma$ if $\sigma$ equals 0.5 or if $u_{c c c}=u_{l c c}=0$; otherwise, $h$ is strictly decreasing in $\sigma$.

(That is, $\phi=1 \Longrightarrow \frac{\mathrm{d}}{\mathrm{d} \sigma} h(\sigma, \tau)=0$ for $\sigma=0.5$ or $u_{c c c}=u_{l c c}=0$; and $\frac{\mathrm{d}}{\mathrm{d} \sigma} h(\sigma, \tau)<0$ for $\sigma \in[0,0.5)$ and $\left(u_{c c c}>0\right.$ or $\left.u_{l c c}<0\right)$.)

Proof. Totally differentiating the first-order condition (6) with respect to $h$ and $\sigma$, we have

$$
\begin{aligned}
& -\left\{(1-\phi) E u_{c}+2(1-\sigma+\phi \sigma) E\left[u_{c c} s_{i}\right]-2 E\left[u_{l c} s_{i}\right]\right\} \mathrm{d} \sigma \\
& \quad+\left\{(1-\sigma+\phi \sigma)\left(E u_{c c}-E u_{c l}\right)+\left(E u_{l l}-E u_{l c}\right)\right\} \mathrm{d} h=0 .
\end{aligned}
$$

\footnotetext{
${ }^{8}$ By definition, a "prudent" agent cautiously supplies extra effort, $h$, in order to buffer future uncertainty, which, in turn, only happens if $u_{c c c}>0$. If agents are risk averse $\left(u_{c c}<0\right)$ but not prudent $\left(u_{c c c}=0\right)$ then consumption and leisure choices will equal their "certainty equivalent” values, as demonstrated by the quadratic utility example presented in Section 5.
} 
This equation implies

$$
\frac{\mathrm{d}}{\mathrm{d} \sigma} h(\sigma, \tau)=\frac{(1-\phi) E u_{c}+2\left\{(1-\sigma+\phi \sigma) E\left[u_{c c} s_{i}\right]-E\left[u_{l c} s_{i}\right]\right\}}{(1-\sigma+\phi \sigma)\left(E u_{c c}-E u_{c l}\right)+\left(E u_{l l}-E u_{l c}\right)} .
$$

Since $u_{c c}<0, u_{l l}<0$, and $u_{c l}=u_{l c} \geq 0$, the denominator on the right-hand side becomes strictly negative. We now want to prove that the numerator is positive. Since the two types of shocks are normalized to be independent, then

$$
\begin{aligned}
E\left[u_{c c} s_{i}\right] & =\int\left\{\int u_{c c} \mathrm{~d} G\left(t_{i}\right)\right\} s_{i} \mathrm{~d} F\left(s_{i}\right), \\
E\left[u_{l c} s_{i}\right] & =\int\left\{\int u_{l c} \mathrm{~d} G\left(t_{i}\right)\right\} s_{i} \mathrm{~d} F\left(s_{i}\right) .
\end{aligned}
$$

Since $c_{i}=h+(1-2 \sigma) s_{i}+(1-2 \tau) t_{i}$ (see equation (6)) and $u_{c c c} \geq 0$,

$$
\frac{\mathrm{d}}{\mathrm{d} s_{i}}\left\{\int u_{c c} \mathrm{~d} G\left(t_{i}\right)\right\}=(1-2 \sigma) \int u_{c c c} \mathrm{~d} G\left(t_{i}\right) \geq 0
$$

holding with equality if and only if $\sigma=0.5$ or $u_{c c c}=0$. So, $\int u_{c c} \mathrm{~d} G\left(t_{i}\right)$ is strictly negative and nondecreasing in $s_{i}$. Since $u_{l c c} \leq 0$, we have

$$
\frac{\mathrm{d}}{\mathrm{d} s_{i}}\left\{\int u_{l c} \mathrm{~d} G\left(t_{i}\right)\right\}=(1-2 \sigma) \int u_{l c c} \mathrm{~d} G\left(t_{i}\right) \leq 0,
$$

holding with equality if and only if $\sigma=0.5$ or $u_{l c c}=0$. So, $\int u_{l c} \mathrm{~d} G\left(t_{i}\right)$ is non-negative and nonincreasing in $s_{i}$. When $F\left(s_{i}\right)$ is symmetric with mean 0 , we, therefore, have $E\left[u_{c c} s_{i}\right] \geq 0$ and $E\left[u_{l c} s_{i}\right] \leq 0$. Accordingly, $(1-\sigma+\phi \sigma) E\left[u_{c c} s_{i}\right]-E\left[u_{l c} s_{i}\right] \geq 0$, holding with equality if and only if $\sigma=0.5$ or $u_{c c c}=u_{l c c}=0$. When $\phi<1$, since $(1-\phi) E u_{c}>0$, we have $\mathrm{d} h / \mathrm{d} \sigma<0$ for all $\sigma \in[0,0.5]$. When $\phi=1$, we have $\mathrm{d} h / \mathrm{d} \sigma \leq 0$, holding with equality if and only if $\sigma=0.5$ or $u_{c c c}=u_{l c c}=0$.

Discussion. Let's first discuss the case in which altruism is not full, followed by the case in which altruism is full.

(1) In words, $\frac{\mathrm{d}}{\mathrm{d} \sigma} h(\sigma, \tau)<0$ implies that households exhibit less effort as the level of risk sharing between households increases. When altruism is not full, $(\phi<1)$, households attempt to take advantage of a greater amount of risk sharing by working less. Each household values an increase in its own leisure but bears only a fraction of the concomitant decrease 
in its own wage income under positive levels of risk sharing. As a result, moral hazard is a problem whether households exhibit prudence $\left(u_{c c c}>0\right)$ or not $\left(u_{c c c}=0\right)$. But when agents are also prudent, the increase in risk sharing, $\sigma$, also reduces their prudence-driven supply of effort, $h$. The reason is that effort level decisions are made before the shocks are realized. Hence, a prudent household will supply less effort in lower risk situations (those associated with more risk sharing). So the effects of moral hazard and prudence work in the same direction to generate less effort as risk sharing increases, thereby allowing us to sign the derivative $\frac{d h}{d \sigma}$ under fairly general conditions.

(2) In words, $\frac{\mathrm{d}}{\mathrm{d} \sigma} h(\sigma, \tau)=0$ means that effort is unaffected by the level of risk sharing. Only when altruism is full, $(\phi=1)$, will household $i[-i]$ place the same value on its own leisure and consumption as that of household $-i[i]$. As a result, only with full altruism will both households not have the incentive to free ride off the risk sharing provided by the other household since there is no moral hazard. So if, in addition, households are not prudent, $\left(u_{c c c}=0\right)$, then their level of effort is unaffected by the level of risk sharing. If, however, households exhibit prudence, $\left(u_{c c c}>0\right)$, then their effort level, $h$, decreases as risk sharing improves even without moral hazard, provided that $\sigma<0.5$.

When altruism is full and $\sigma=0.5$, effort is unaffected by a small change in $\sigma$. The reason is that the functional $h(\sigma, \cdot)$ is parabolic in $\sigma$ over the domain $[0,1]$ with a minimum at $\sigma=0.5$. To understand this fact intuitively, suppose that we hypothetically raised $\sigma$ above 0.5 , that is, outside of its proper domain $[0,0.5] .{ }^{9}$ Whereas full risk sharing occurs at $\sigma=0.5$, equation (3) shows that risk sharing would actually be reduced at values of $\sigma$ above 0.5. (In the extreme case where $\sigma=1.0$, for example, both households would simply swap the full amount of their risks with each other without actually sharing any of it.) In other words, any deviation from 0.5 reduces risk sharing. Since households are prudent, their chosen level of effort, $h$, therefore, must increase if $\sigma$ is set above 0.5 , in the same way that effort must increase if $\sigma$ is set below 0.5. Hence, $\sigma=0.5$ is the minimum of the parabola $h(\sigma, \cdot)$ and so $\frac{\mathrm{d}}{\mathrm{d} \sigma} h(\sigma, \tau)=0$ at $\sigma=0.5$.

\footnotetext{
${ }^{9}$ In fact, we could allow $\sigma$ and $\tau$ to be defined over [0.0,1.0]. But it is easy to show that points above 0.5 would never be chosen in equilibrium. In particular, if $\phi<1$ then moral hazard becomes larger for points above 0.5 ; the same amount of risk sharing can be obtained with less moral hazard by chosing points below 0.5 . If $\phi=1.0$, then, as shown in Section 4, full risk sharing (0.5) is optimal; a point above 0.5 would lower risk sharing.
} 
Lemma 2 (Impact of $\tau$ on effort, $h$ ) Regardless of the level of altruism (that is, $0 \leq \phi \leq 1$ ), the optimal level of effort, $h$, is unaffected by a small change in $\tau$ if $\tau$ equals 0.5 or if $u_{c c c}=u_{l c c}=0$; otherwise, effort, $h$, is strictly decreasing in $\tau$.

(That is, $\frac{\mathrm{d}}{\mathrm{d} \tau} h(\sigma, \tau)=0$ for $\tau=0.5$ or $u_{c c c}=u_{l c c}=0 ; \frac{\mathrm{d}}{\mathrm{d} \tau} h(\sigma, \tau)<0$ for $\tau \in[0,0.5)$ and $\left(u_{c c c}>0\right.$ or $\left.u_{l c c}<0\right)$.)

Proof. Totally differentiating (6) with respect to $\tau$ and $h$, we have

$$
\begin{aligned}
& -2\left\{(1-\sigma+\phi \sigma) E\left[u_{c c} t_{i}\right]-E\left[u_{l c} t_{i}\right]\right\} \mathrm{d} \tau \\
& \quad+\left\{(1-\sigma+\phi \sigma)\left(E u_{c c}-E u_{c l}\right)+\left(E u_{l l}-E u_{l c}\right)\right\} \mathrm{d} h=0 .
\end{aligned}
$$

This implies

$$
\frac{\mathrm{d} h}{\mathrm{~d} \tau}=\frac{2\left\{(1-\sigma+\phi \sigma) E\left[u_{c c} t_{i}\right]-E\left[u_{l c} t_{i}\right]\right\}}{(1-\sigma+\phi \sigma)\left(E u_{c c}-E u_{c l}\right)+\left(E u_{l l}-E u_{l c}\right)} .
$$

Since $u_{c c}<0, u_{l l}<0$, and $u_{c l}=u_{l c} \geq 0$, the denominator of the right-hand side is strictly negative. Similarly to the previous proof, we can show that $E\left[u_{c c} t_{i}\right] \geq 0$ and $E\left[u_{l c} t_{i}\right] \leq 0$. Hence, $(1-\sigma+\phi \sigma) E\left[u_{c c} t_{i}\right]-E\left[u_{l c} t_{i}\right] \geq 0$, holding with equality if and only if $\tau=0.5$ or $u_{c c c}=u_{l c c}=0$. So, $\mathrm{d} h / \mathrm{d} \tau \leq 0$, holding with equality if and only if $\tau=0.5$ or $u_{c c c}=u_{l c c}=0$.

Discussion. Comparing the last two lemmas, notice that the relationship between the level of effort, $h$, and the amount of observable risk that is shared, $\tau$, is similar to the response of effort to the amount of nonobservable shock that is shared, $\sigma$, under full altruism ( $\phi=$ 1). Intuitively, there is no private information contained in observable shocks; and when shocks are unobservable, there is no desire to take advantage of the private information when altruism is full. Hence, in both cases, the direct role of moral hazard is not present. However, notice from equation (8) that $\mathrm{d} h / \mathrm{d} \tau$ is not independent of $\sigma$ unless $u_{c c c}=u_{l c c}=0$ (that is, unless agents are not prudent). In other words, the change in the effort level in response to a change in $\tau$ cannot be determined independently from $\sigma$ since $\sigma$ also affects the optimal choice for $h$. The interdependence of $\sigma$ and $\tau$ is discussed in Section 6.

\section{The Optimal Risk-Sharing Arrangement $(\sigma, \tau)$}

This section derives the first-best and second-best optimal risk-sharing arrangements $(\sigma, \tau)$. As proven below, if first-best risk-sharing arrangements were available (that is, all shocks 
were observable), then shocks would be fully insurable. Similarly, full insurance is optimal in the second-best equilibrium provided that agents are fully altruistic $(\phi=1)$. In both of those cases, moral hazard does not exist because either agents have no private information (as in the first-best equilibrium) or agents have no incentive to take advantage of their private information (as with full altruism).

In the more general case, when private information exists and altruism is not full, $(\phi<$ 1), moral hazard becomes relevant. The optimal risk-sharing arrangement, therefore, must balance the benefits of risk sharing against the costs of moral hazard. Moral hazard prevents full risk sharing. Still, we demonstrate that observable shocks will be fully shared provided that preferences satisfy a condition that we derive. In other words, Ricardian equivalence can hold in the presence of incomplete risk sharing.

Lemma 3 The optimal risk-sharing arrangement $(\sigma, \tau)$ solves the following set of equations:

$$
(1-\phi) \sigma h_{\sigma} E u_{c}-2 E\left[u_{c} s_{i}\right]=0
$$

and

$$
(1-\phi) \sigma h_{\tau} E u_{c}-2 E\left[u_{c} t_{i}\right]=0 .
$$

Proof. By the symmetric shock assumption,

$$
E\left[u\left(c_{i}, l_{i}\right)+\phi u\left(c_{-i}, l_{-i}\right)\right]=(1+\phi) E u\left(c_{i}, l_{i}\right) .
$$

The optimal insurance combination $(\sigma, \tau)$ is obtained by solving

$$
\max _{\sigma, \tau} E u\left(c_{i}, l_{i}\right)=E u\left(h(\sigma, \tau)+(1-2 \sigma) s_{i}+(1-2 \tau) t_{i}, 1-h(\sigma, \tau)\right) .
$$

The first-order conditions are

$$
h_{\sigma} E u_{c}-2 E\left[u_{c} s_{i}\right]-h_{\sigma} E u_{l}=0
$$

and

$$
h_{\tau} E u_{c}-2 E\left[u_{c} t_{i}\right]-h_{\tau} E u_{l}=0 .
$$

Use of the first-order condition for $h$, or equation (5), to eliminate $E u_{l}$ from the above equations produces equations (9) and (10). 


\subsection{First-Best Risk Sharing}

The previous lemma nests the solutions to the first-best and second-best equilibrium. To get the first-best equilibrium, we can simply normalize $s_{i}=0$ to remove the unobservable shock, leaving only the observable shock. ${ }^{10}$

Proposition 4 With only observable shocks $\left(s_{i}=0\right)$, risk is fully shared (that is, $\tau=0.5$ ).

Proof. If there are no unobservable shocks, $\left(s_{i}=0\right)$, no risk sharing based on the labor income $y_{i}$ and $y_{-i}$ is needed, that is, $\sigma=0$. Hence, equation (10) implies that $2 E\left[u_{c} t_{i}\right]=0$ where

$$
E\left[u_{c} t_{i}\right]=\int\left\{\int u_{c} \mathrm{~d} F\left(s_{i}\right)\right\} t_{i} \mathrm{~d} G\left(t_{i}\right)
$$

Since $u_{c c}<0$, we have

$$
\frac{\mathrm{d}}{\mathrm{d} t_{i}}\left\{\int u_{c} \mathrm{~d} F\left(s_{i}\right)\right\}=(1-2 \tau) \int u_{c c} \mathrm{~d} F\left(s_{i}\right) \leq 0,
$$

holding with equality if and only if $\tau=0.5$. When $G\left(t_{i}\right)$ is symmetric with mean 0 , we have $E\left[u_{c} t_{i}\right]=0$ if and only if $\tau=0.5$.

Discussion. In the first-best economy, there is no moral hazard. Full risk sharing, therefore, is always desirable in the presence of concave preferences. Risk sharing reduces (or eliminates in the case of symmetric shocks) the variability in income of each agent without reducing the expected income. This result is analogous to the standard result in insurance economics that full insurance is optimal if there are no premium loads.

\subsection{Second-Best Risk Sharing}

We now derive the second-best risk-sharing arrangements in the presence of unobservable shocks, that is, when $F\left(s_{i}\right)$ is not degenerate. We first consider the case of full altruism, $(\phi=1)$, followed by the more general case of nonfull altruism, $(\phi<1)$.

\footnotetext{
${ }^{10}$ Alternatively, we could have two observable shocks by specifying $F\left(s_{i}\right)=0$ for all $s_{i}<\hat{s}$, and $F\left(s_{i}\right)=$ 1 for all $s_{i}>\hat{s}$ for some $\hat{s}$ (the atom of the distribution). In this case, it is easy to show that both observable shocks will be fully shared, that is, $(\sigma, \tau)=(0.5,0.5)$. The single shock in the text can be interpreted as the simple sum of two shocks.
} 


\subsubsection{Full Altruism $(\phi=1)$}

Proposition 5 When two households are fully altruistic to each other, perfect insurance is optimal for both unobservable and observable shocks, that is, $\phi=1 \Longrightarrow\left(\sigma^{*}, \tau^{*}\right)=$ $(0.5,0.5)$.

Proof. When $\phi=1$, the first-order conditions, (9) and (10), imply

$$
E\left[u_{c} s_{i}\right]=\int\left\{\int u_{c} \mathrm{~d} G\left(t_{i}\right)\right\} s_{i} \mathrm{~d} F\left(s_{i}\right)=0
$$

and

$$
E\left[u_{c} t_{i}\right]=\int\left\{\int u_{c} \mathrm{~d} F\left(s_{i}\right)\right\} t_{i} \mathrm{~d} G\left(t_{i}\right)=0 .
$$

Since $u_{c c}<0$, we have

$$
\frac{\mathrm{d}}{\mathrm{d} s_{i}}\left\{\int u_{c} \mathrm{~d} G\left(t_{i}\right)\right\}=(1-2 \sigma) \int u_{c c} \mathrm{~d} G\left(t_{i}\right) \leq 0,
$$

which holds with equality if and only if $\sigma=0.5$. When $F\left(s_{i}\right)$ is symmetric with mean 0 , we have $E\left[u_{c} s_{i}\right] \leq 0$ with equality if and only if $\sigma=0.5$. Hence, $\sigma^{*}=0.5$ is required for $E\left[u_{c} s_{i}\right]=0$ to hold. Similarly, $E\left[u_{c} t_{i}\right] \leq 0$ holds with equality if and only if $\tau^{*}=0.5$.

\subsubsection{Altruism Less Than Full $(\phi<1)$}

Proposition 6 When two households are not fully altruistic to each other, the second-best level of risk sharing for the unobservable shock is less than full, that is, $\phi<1 \Longrightarrow \sigma^{*} \in$ $(0,0.5)$.

Proof. By Lemma $1, h_{\sigma}=\mathrm{d} h / \mathrm{d} \sigma<0$ for all $\sigma \in[0,0.5]$. By assumption, $\phi<1$. By the previous proof, $E\left[u_{c} s_{i}\right] \leq 0$ with equality if and only if $\sigma=0.5$. So, when $\sigma=0$, the left-hand side of equation (9) becomes

$$
(1-\phi) \sigma h_{\sigma} E u_{c}-2 E\left[u_{c} s_{i}\right]=-2 E\left[u_{c} s_{i}\right]>0 .
$$

When $\sigma=0.5$,

$$
(1-\phi) \sigma h_{\sigma} E u_{c}-2 E\left[u_{c} s_{i}\right]=(1-\phi) \sigma h_{\sigma} E u_{c}<0
$$


Since the left-hand side of equation (9) is continuous for all $\sigma \in[0,0.5]$, the optimal $\sigma$ that satisfies equation (9) exists and $\sigma^{*} \in(0,0.5)$. Moreover, since the left-hand side of equation (9) is positive at $\sigma=0$ and it is negative at $\sigma=0.5$, then the second-order requirement for a maximum is also satisfied.

Proposition 7 A sufficient condition ${ }^{11}$ for observable shocks to be fully shared $\left(\tau^{*}=0.5\right)$ that is, for Ricardian equivalence to hold-is

$$
E\left[u_{c} t_{i}\right]\left\{\Phi E\left[u_{c c} s_{i}\right]-E\left[u_{l c} s_{i}\right]\right\} \leq E\left[u_{c} s_{i}\right]\left\{\Phi E\left[u_{c c} t_{i}\right]-E\left[u_{l c} t_{i}\right]\right\},
$$

where $\Phi=1-\sigma+\phi \sigma$.

Proof. Similar to the proof for Lemma 1, it can be shown that $\tau=0.5$ implies $E\left[u_{c c} t_{i}\right]=$ $E\left[u_{l c} t_{i}\right]=E\left[u_{c} t_{i}\right]=0$. From equation (8), $h_{\tau}=0$. Thus the first-order condition (10) holds for all $\sigma \in[0,0.5]$. The first-order conditions, (9) and (10), along with equations (7) and (8), imply

$$
\frac{E\left[u_{c} t_{i}\right]}{E\left[u_{c} s_{i}\right]}=\frac{h_{\tau}}{h_{\sigma}}=\frac{\Phi E\left[u_{c c} t_{i}\right]-E\left[u_{l c} t_{i}\right]}{\frac{1}{2}(1-\phi) E u_{c}+\Phi E\left[u_{c c} s_{i}\right]-E\left[u_{l c} s_{i}\right]},
$$

where $\Phi=1-\sigma+\phi \sigma$. Since $E u_{c}>0$, a necessary condition for $\tau^{*}$ to be less than 0.5 is

$$
\frac{E\left[u_{c} t_{i}\right]}{E\left[u_{c} s_{i}\right]}<\frac{\Phi E\left[u_{c c} t_{i}\right]-E\left[u_{l c} t_{i}\right]}{\Phi E\left[u_{c c} s_{i}\right]-E\left[u_{l c} s_{i}\right]}
$$

at $\tau^{*}$. In other words, a sufficient condition for $\tau^{*}=0.5$ is $\frac{E\left[u_{c} t_{i}\right]}{E\left[u_{c} s_{i}\right]} \geq \frac{\Phi E\left[u_{c c} t_{i}\right]-E\left[u_{l c} t_{i}\right]}{\Phi E\left[u_{c c} s_{i}\right]-E\left[u_{l c} s_{i}\right]}$. Since $E\left[u_{c} t_{i}\right]<0$ and $E\left[u_{c} s_{i}\right]<0$, the inequality (11), therefore, is a sufficient condition for $\tau^{*}=0.5$.

Proposition 8 In the special case in which utility is separable $\left(u_{c l}=u_{l c}=0\right)$, a suffcient condition for observable shocks to be fully shared $\left(\tau^{*}=0.5\right)$-that is, for Ricardian equivalence to hold-is

$$
E\left[u_{c} t_{i}\right] E\left[u_{c c} s_{i}\right] \leq E\left[u_{c} s_{i}\right] E\left[u_{c c} t_{i}\right] .
$$

Proof. By assumption, $E\left[u_{l c} s_{i}\right]=E\left[u_{l c} t_{i}\right]=0$. From Proposition 7, the inequality (12) is a sufficient condition for $\tau^{*}=0.5$.

\footnotetext{
${ }^{11}$ Of course, the necessary and sufficient conditions for Ricardian equivalence are that equations (9) and (10) hold with $\tau^{*}=0.5$ and $\sigma^{*} \leq 0.5$.
} 
Corollary 9 (Existence of $\left(\sigma^{*}, \tau^{*}\right)$ ) If condition (11) or (12) holds, then a second-best risksharing arrangement, $\left(\sigma^{*}, \tau^{*}\right)$, exists in which Ricardian equivalence holds despite the presence of imperfect risk sharing $\left(0<\sigma^{*}<0.5 ; \tau^{*}=0.5\right)$.

Discussion. Two observations are in order. First, notice that degree of altruism does not play an important role in the first-best equilibrium, but it does play an important role in the second-best equilibrium. As emphasized by Barro (1974, 1996), the degree of altruism itself is not critical for Ricardian equivalence to hold in the standard deterministic altruisticlinkage model or, similarly, in the first-best equilibrium in the case of uncertainty. As long as altruism is strong enough for intergenerational transfers (in either direction) to be operative, all shocks will be fully shared between parents and their children in the first-best equilibrium. In the second-best equilibrium, however, the degree of altruism plays a critical role in limiting the degree to which unobservable shocks are shared. Only if altruism is full, $(\phi=1)$, will all shocks be fully shared in the second-best equilibrium because only then do parents and children not have the incentive to take advantage of their private information. When altruism is less than full, $(\phi<1)$, only observable shocks will be fully shared in equilibrium.

Second, the inequality (11) or (12) is not strong enough to rule out the possibility of multiple second-best equilibria. Stronger conditions on the utility function are required to ensure uniqueness. We do not derive the conditions required for uniqueness in this paper because that issue is both quite complicated and unnecessary for our purposes. (The next section, however, does provide several examples of preferences for which the equilibrium is unique.) Even if multiple equilibria exist for a particular utility function, the above analysis proves that risk sharing will be incomplete at each equilibrium; however, Ricardian equivalence still holds for any utility function satisfying (11) or (12).

\section{Examples: Quadratic, CARA, and CRRA}

The previous section demonstrated that the second-best level of risk sharing for the unobservable shock is generally less than full (except when $\phi=1$ ) but that the observable shock might be fully shared, that is, Ricardian equivalence holds in the presence of incomplete household risk sharing. This section explores some examples of preferences in which Ricar- 
dian equivalence holds, including quadratic, Constant Absolute Risk Aversion (CARA), and Constant Relative Risk Aversion (CRRA). Analytical results can be provided for the cases of quadratic and CARA utility but, not surprisingly, we must rely on numerical calculations for the CRRA case where closed-form solutions are impossible.

Example 10 (Proposition) When the utility function, $u(c, l)$, is separable in consumption and leisure, and its consumption part takes the quadratic form, full insurance for an observable shock is optimal, that is, $\tau^{*}=0.5$.

Proof. When the utility function is quadratic, $u_{c c c}=0$. Then,

$$
\begin{aligned}
\frac{\mathrm{d}}{\mathrm{d} s_{i}}\left\{\int u_{c c} \mathrm{~d} G\left(t_{i}\right)\right\} & =(1-2 \sigma) \int u_{c c c} \mathrm{~d} G\left(t_{i}\right)=0, \\
\frac{\mathrm{d}}{\mathrm{d} t_{i}}\left\{\int u_{c c} \mathrm{~d} F\left(s_{i}\right)\right\} & =(1-2 \tau) \int u_{c c c} \mathrm{~d} F\left(s_{i}\right)=0 .
\end{aligned}
$$

When $F\left(s_{i}\right)$ and $G\left(t_{i}\right)$ are symmetric with mean $0, E\left[u_{c c} s_{i}\right]=E\left[u_{c c} t_{i}\right]=0$. Thus, the sufficient condition (12) holds with equality.

Example 11 (Proposition) When the utility function, $u(c, l)$, is separable in consumption and leisure, and its consumption part is one of constant absolute risk aversion, full insurance for an observable shock is optimal, that is, $\tau^{*}=0.5$.

Proof. When the utility function is CARA with the coefficient of absolute risk aversion $\eta$, we have $u_{c c}=-\eta u_{c}$ for all $s_{i}$ and $t_{i}$. Then,

$$
E\left[u_{c} t_{i}\right] E\left[u_{c c} s_{i}\right]=E\left[u_{c} t_{i}\right] E\left[-\eta u_{c} s_{i}\right]=E\left[-\eta u_{c} t_{i}\right] E\left[u_{c} s_{i}\right]=E\left[u_{c c} t_{i}\right] E\left[u_{c} s_{i}\right] .
$$

The sufficient condition (12) holds with equality.

Example 12 (Conjecture) When the utility function is separable and its consumption part is one of constant relative risk aversion with the coefficient of relative risk aversion $\gamma \geq 0$, full insurance for an observable shock is optimal, that is, $\tau^{*}=0.5$.

Discussion. The CRRA example above is labeled a "conjecture” because closed-form solutions are not possible with CRRA utility. Instead, we constructed a computer program (written in Maple and run with 30 digits precision) that used a grid search algorithm to solve for the global optimum, $\left(\tau^{*}, \sigma^{*}\right) \in[0,0.5] \times[0,0.5]$, for a given set of utility parameters. 
Table 2: Optimal Level of Sharing of Observable and Nonobservable Shocks

\begin{tabular}{c|cc}
\hline$\gamma$ & $\tau^{*}$ & $\sigma^{*}$ \\
\hline 0.5 & 0.50 & 0.04 \\
1.0 & 0.50 & 0.11 \\
1.5 & 0.50 & 0.18 \\
2.0 & 0.50 & 0.23 \\
5.0 & 0.50 & 0.40 \\
\hline
\end{tabular}

This grid search algorithm was then run over a large range of utility parameters. In each case, $\tau^{*}=0.50$

Table 2 presents some illustrative numerical results for the CRRA specification: $\frac{c^{1-\gamma}}{1-\gamma}+$ $\beta \cdot \frac{l^{1-\gamma}}{1-\gamma}$, where $\beta$ is set to unity. Obviously, this example is not intended to be a carefully calibrated numerical experiment. Rather, our intention was to demonstrate the role of the risk aversion parameter, $\gamma$, in determining the optimal risk-sharing arrangement, $\left(\tau^{*}, \sigma^{*}\right)$. Notice that $\tau^{*}=0.50$ in each case, that is, the observable shock is always fully shared. Notice also that the $\sigma^{*}$ is increasing in $\gamma$. One reason that $\sigma^{*}$ increases is that moral hazard becomes less important at higher levels of $\gamma$; in particular, agents that are very prudent have less incentive to try to free ride off the risk sharing provided by the other agent. To see why, recall that agent $i$ 's pretax income is $y_{i}=h_{i}+s_{i}$. Less free riding (that is, higher $h_{i}$ ) reduces agent $i$ 's probability of suffering from a low value of $y_{i}$ after the unobservable shock $s_{i}$ is realized. As a result, more risk can be optimally shared among more prudent agents, since they are less likely to try to take advantage of it. Another reason that $\sigma^{*}$ increases in $\gamma$ is that the utility value of risk sharing increases in $\gamma$. As a result, the balance between controlling moral hazard and providing risk sharing shifts toward more risk sharing as the value of $\gamma$ increases.

\section{The Joint Determination of $\tau^{*}$ and $\sigma^{*}$ in the Second-Best Econ- omy}

Thus far, we have proven that (i) all shocks will be fully shared in the first-best economy, whereas (ii) the nonobservable shock will only be partially shared in the second-best economy. Both of those results were proven to hold provided that the derivatives, cross- 
derivatives, and higher-order derivatives of the utility function satisfy some fairly general conditions that were stated in the beginning of Section 2. We then showed that (iii) the observable shock may be fully shared in the second-best equilibrium. However, in proving result (iii), we specified an additional sufficient condition, (11). The presence of that additional condition leads to an interesting question: why wasn't an extra sufficient condition used to demonstrate full risk sharing in the first-best economy, result (i)? In other words, if a shock is fully observable, does it really matter if nonobservable shocks are also present, as in the second-best economy? In still other words, why doesn't result (iii) immediately follow from results (i) and (ii), thereby allowing us to avoid the additional sufficient condition (11) that we used to prove result (iii)? This section answers those questions by demonstrating the interdependence of $\tau^{*}$ and $\sigma^{*}$ in the second-best economy whenever agents are prudent.

As noted in Section 2, equation (8) shows that $\mathrm{d} h / \mathrm{d} \tau$ is not independent of $\sigma$ unless $u_{c c c}=u_{l c c}=0$ (that is, unless agents are not prudent). As a result, we generally cannot set $\tau^{*}$ and $\sigma^{*}$ independently of each other in the second-best economy (unless agents are not prudent). In contrast, all shocks can, of course, be independently shared in the first-best economy where complete contracting is available.

We now illustrate the joint determination of $\tau^{*}$ and $\sigma^{*}$ in the second-best economy using the CRRA example considered in the previous section with $\gamma=0.5$. Table 3 reports the agent's level of effort, $h$, and utility, $u$, at the second-best equilibrium tuple $\left(\tau^{*}, \sigma^{*}\right)=$ $(0.50,0.04)$ as well as at two nonequilibrium values of $(\tau, \sigma)$. Of course, the highest level of utility is at the second-best equilibrium point, which is marked in Table 3 with asterisks (*). But now consider the other two nonequilibrium tuples where the level of risk sharing for the unobservable shock is set above its optimal level (that is, $\sigma>\sigma^{*}$ ). Notice that the tuple $(\tau, \sigma)=(0.50,0.50)$, where both shocks are fully shared, generates less effort and lower utility than the tuple $(\tau, \sigma)=(0.00,0.50)$, where the observable shock is not shared at all. In other words, the "third-best" (that is, constrained) outcome does not necessarily fully share the observable shock when the unobservable shock is being shared too much relative to its second-best level. The reason is prudence. When $\sigma>\sigma^{*}$, too much of the unobservable risk is being shared, so the level of effort exerted by each household is below its optimal level. Setting $\tau<0.50$, therefore, forces households to accept more risk associated with the 
Table 3: Utility Levels at Equilibrium and Various Nonequilibrium Risk-Sharing Arrangements

\begin{tabular}{cc|cc}
\hline$\tau$ & $\sigma$ & $h$ & $u$ \\
\hline $0.50^{*}$ & $0.04^{*}$ & $0.486^{*}$ & $2.822^{*}$ \\
0.50 & 0.50 & 0.200 & 2.683 \\
0.00 & 0.50 & 0.227 & 2.687 \\
\hline
\end{tabular}

observable shock and, hence, exert more effort, thereby reducing the moral hazard problem associated with sharing the unobservable shock.

In sum, the values of $\tau^{*}$ and $\sigma^{*}$ cannot be determined independently in the secondbest economy in the presence of prudent agents. The sufficient condition (11) guarantees, though, that observable shocks will be fully shared at equilibrium. That sufficient condition is not needed in the first-best equilibrium where it is always efficient to share a given risk, independent of how other risks are shared.

\section{Conclusion}

This paper demonstrates that Ricardian equivalence can hold even in the presence of incomplete risk sharing between parents and their children. Moral hazard prevents unobservable idiosyncratic shocks from being fully shared. But observable shocks, including public changes in the timing of taxes, are fully shared in equilibrium under a sufficient condition derived herein. We considered several specifications for preferences in which Ricardian equivalence holds, including separable quadratic, separable CARA, and separable CRRA. (Closed-form solutions are not available in the CRRA case, so we can only conjecture that Ricardian equivalence holds on the basis of numerical simulations.) Future work could extend our results to an even larger class of utility functions, although we found it difficult to obtain closed-form solutions more generically. Future empirical work using linked household-level data could also attempt to distinguish between nonobservable and observable shocks, such as Social Security reforms. Performing such estimation, however, would be quite challenging at present; modern data sets do not yet span a long enough period containing many policy shocks. Still, Villanueva (2001) provides some indirect evidence that among children with spouses, parents are more likely to transfer resources when the child's household primary 
earner loses income than when the secondary earner loses income. Since secondary earners have less attachment to the labor force, their level of effort becomes a relatively more important source of moral hazard, and so this empirical result is consistent with the our model. 


\section{References}

[1] Altonji, Joseph G., Fumio Hayashi, and Laurence J. Kotlikoff (1992). "Is the Extended Family Altruistically Linked? Direct Tests Using Micro Data.” American Economic Review, 82, 5: 1177-1198.

[2] Altonji, Joseph G., Fumio Hayashi, and Laurence J. Kotlikoff (1997). "Parental Altruism and Inter Vivos Transfers: Theory and Evidence.” Journal of Political Economy, 105, 6: 1121-1166.

[3] Altuğ, Sumru and Pamela Labadie (1994). Dynamic Choice and Asset Markets. Academic Press: New York.

[4] Barro, Robert J. (1974). “Are Government Bonds Net Wealth?” Journal of Political Economy, 82 (November/December): 1095-1118.

[5] Barro, Robert J. (1998). “Reflections on Ricardian Equivalence.” In Maloney, John, ed, Debt and deficits: An historical perspective. 1998, pp. 47-59.

[6] Bernheim, B. Douglas (1987). "Ricardian Equivalence: An Evaluation of Theory and Evidence,” in NBER Macroecnomics Annual 1987, Stanley Fischer, Ed., MIT Press: Cambridge, Mass.: 263-304.

[7] Bernheim, B. Douglas (1991). "How Strong are Bequest Motives? Evidence Based on Estimates of the Demand for Life Insurance and Annuities.” Journal of Political Economy, 99 (2): 899-927.

[8] Cochrane, J. (1991). “A Simple Test of Consumption Insurance.” Journal of Political Economy, 99: 957-976.

[9] Congressional Budget Office (1998). "Social Security and Private Saving: A Review of the Empirical Evidence.” CBO Memorandum, Washington, DC. (Available at www.cbo.gov.) 
[10] Cox, Donald, Bruce Hansen, and Emmanuel Jimenez (2004). "How Responsive are Private Transfers to Income? Evidence from a Laissez-Faire Economy.” Journal of Public Economics, vol. 88, no. 9-10: 2193-2219.

[11] Elmendorf, Douglas and N. Gregory Mankiw (1999). “Government Debt,” in Handbook of Macroeconomics, John B. Taylor and M. Woodford, Eds., Elsevier Science B.V.: 1615-1669.

[12] Hayashi, Fumio, Joseph Altonji, and Laurence J. Kotlikoff (1996). "Risk-Sharing Between and Within Families.” Econometrica, 64, 2: 261-294.

[13] Mace, Barbara J. (1991). "Full Insurance in the Presence of Aggregate Uncertainty." Journal of Political Economy, 99: 928-956.

[14] Page, Benjamin (2003). "Bequest Taxes, Inter Vivos Transfers, and the Bequest Motive.” Journal of Public Economics, 87, 5-6: 1219-29

[15] Ricardo, David (1951). "On the Principles of Political Economy and Taxation (3rd edition).” Reprinted in P. Sraffa, ed., Works and Correspondence of David Ricardo, v. I, Cambridge, Cambridge University Press.

[16] Seater, John (1993). “Ricardian Equivalence.” Journal of Economics Literature, 31: 142-190.

[17] Slemrod, Joel (1995). "Professional Opinions About Tax Policy.” National Tax Journal, March, 48: 121-147.

[18] Smetters, Kent (1999). “Ricardian Equivalence: Long-Run Leviathan.” Journal of Public Economics, 73: 395-421.

[19] Tomes, Nigel (1981). “The Family, Inheritance, and the Intergenerational Transmission of Inequality.” Journal of Political Economy, 89 (5): 928-958.

[20] Townsend, Robert M. (1994). “Risk and Insurance in Village India.” Econometrica, 62: 539-591. 
[21] Villanueva, Ernesto (2001). "Parental Altruism under Imperfect Information: Theory and Evidence.” Mimeo, Universitat Pompeu Fabra.

[22] Weil, Philippe (1989). “Overlapping Families of Infinitely-Lived Agents.” Journal of Public Economics, 38: 183-198.

[23] Wilhelm, Mark O. (1996). “Bequest Behavior and the Effect of Heirs’ Earnings: Testing the Altruistic Model of Bequests.” American Economic Review, 86, 4: 874-892. 